\title{
PERSONALIDADE JURÍDICA DA SOCIEDADE IRREGULAR *
}

\author{
J. LAMARTINE CORREAA DE OLIVEIRA
}

Docente Livre de Direito Civil. Professor de Direito Civil na Fac. de Direito da Universidade Católica do Paraná.

\section{I - INTRODUÇÃO. OBJETIVOS E ATUALIDADE DO TRABALHO. SEU PLANO.}

Não é nossa intenção oferecer um quadro completo, um estudo exaustivo, precedido de recensão de tudo o que já se escreveu sôbre $\circ$ assunto, aqui e no estrangeiro. $E^{\prime}$ tal a riqueza bibliográfica que o tema da pessoa jurídica oferece, desde o século XIX, que um tal intuito transbordaria fatalmente dos limites de um artigo de revista para os de uma verdadeira tese ou monografia. Desejamos apenas fornecer algumas perspectivas, a nosso ver omitidas com enorme freqüência, na discussão de tal problema. A oportunidade atual, de estudo e discussão dos projetos de novas codificações, submetidos pelo Govêrno da União ao Congresso Nacional, torna atualíssimo o tema. De nossa parte, estamos convencidos da infelicidade da solução adotada pelos doutos autôres dos Anteprojetos e ilustres Comissões Revisoras. Acreditamos que um equacionamento do problema sob perspectivas ao menos não muito usuais ajude a demonstrar o acêrto de nossa crítica.

Por isso, a finalidade dêste trabalho está na formulação de um esbôço de solução doutrinária para o problema da sociedade irregular, que acreditamos deva ser considerada, de lege lata e de lege ferenda (neste ponto, em desacôrdo frontal, com os ilustrados privatistas autores dos Projetos) como verdadeira pessoa jurídica. Dessa solução dou trinária decorrem imediatas conclusões, na linha de sugestões ao trabalho codificador, embora não as tenhamos redigido sob forma de artigos.

\footnotetext{
* Por ocasião da defesa de nossa tese "CONCEITO DA PESSOA JURIDICA", recebemos, da parte de nossos examinadores, um cordial desafio - o de retirar de modo mais explícito, particularizado e concreto, certas conclusões de Direito Positivo, apenas esboçadas na tese. Foi o que pretendemos fazer com os dois trabalhos: "A Personalidade Jurídica da Família", publicado na revista "JURíDICA" do Instituto do Açucar e do Alcool, n.0 90, julho-setembro de 1965, "A personalidade jurídica da sociedade irregular", publicado originalmente neste número desta revista.

Com isso, pretendemos responder ao cordial desafio que recebemos ao nos tornarmos docentelivre.

Fazêmo-lo com a consciência de que se tratam de estudos incompletos mas que terão sua utilidade na pesquisa de dois aspectos fundamentais da fascinante e riquíssima problemática da pessoa jurídica.
} 
Essa elaboração, será, no curso dêste trabalho, precedida de breve estudo das posições essenciais da doutrina e da lei brasileira, no particular, no curso da qual alguns pontos de nossa própria posição serão adiantados.

Como a conclusão a que chegamos decorre de uma posição mais ampla e geral, no plano conceitual da pessoa jurídica, nós nos permitimos, embora superficialmente, e sem a necessária demonstração, estender algumas considerações sôbre o problema das associações e fundações, na hipótese de inexistência de registro. E situamos todo o problema dentro de uma visão coerente e harmônica do problema global da pessoa jurídica.

\section{II - O ESTADO DA QUESTÃO NA DOUTRINA E LEGISLAÇÃO BRASILEIRAS}

\section{A) OBSERVAÇÕES PRELIMINARES}

Deixemos claro, inicialmente, que não nos ocuparemos, neste trabalho, da distinção (lançada entre nós, por J. X. CARVALHO DE MENDONÇA, no vol. III do seu "Tratado de Direito Comercial Bra sileiro") entre sociedade irregular e sociedade de fato. Dentre os civilistas brasileiros contemporâneos, o saudoso SERPA LOPES (1) foi dos que mais valorizaram a famosa distinção. Consideradas sociedades irregulares aquelas cujo contrato social não tenha sido levado a registro, e sociedades de fato aquelas cujo contrato social seja nulo, ou verbal, o pranteado magistrado e professor carioca daí retirava conseqüências jurídicas no que tange à inaplicabilidade ao primeiro tipo de sociedades de fato (contrato nulo) de certos princípios aplicáveis às demais, de fato e irregulares. Particularmente, quanto à inaplicabilidade do art. 673 do Código de Processo Civil às sociedades de contrato nulo por ilicitude de objeto (2). De nossa parte, como adiante será tornado claro, entendemos que o problema da sociedade de objeto ilícito é problema que nada tem a ver com o da sociedade irregular. $E^{\prime}$ problema que exige tratamento doutrinário e legal inteiramente distinto do problema da mera ausência de satisfação de formalidades legais. Quando a sociedade possui objeto ilícito, não se the pode atribuir o caráter de sociedade, por falta de requisitos de ordem ontológica. $E^{\prime}$ o seu próprio ser que não se configura como o ser de uma sociedade. Quanto ao mais, possua a sociedade contrato verbal ou contrato escrito não registrado, o problema é de irregularidade, sendo irrelevante no particular, para os fins dêste estudo, a distinção entre sociedades irregulares e de fato.

(1) M. M. de SERPA LOPES, "Curso de Direito Civil", ed. Freitas Bastos, Rio, 1958, vol. I, pág. 520.

(2) Idem, n. 810, pág. 524. 
Uma outra observação preliminar deve ser feita: a de que é pacífica entre nossos autôres a afirmação de que, entre os dois sistemas radicais, o da concessão da personalidade jurídica por concessão estatal, sistema francês, sobretudo em matéria de associações, por reminiscência da luta contra a "main morte", e o sistema da plena liberdade de formação das pessoas jurídicas, optou o Direito brasileiro pelo chamado sistema das disposições normativas. Na conceituação de CAIO MÁRIO DA SILVA PEREIRA (3), em tal sistema, "salvo casos especiais de exigência de autorização, o princípio dominante é - de que a vontade dos indivíduos, obedecendo a requisitos predeterminados, é dotada do poder de criar a pessoa jurídica". Na verdade, entendemos que uma correta solução do problema de que nos estamos ocupando exige uma revisão do conceito e estrutura do próprio "sistema das disposições normativas". A qual será feita infra.

\section{B) O CÓDIGO COMERCIAL E A POSIÇÃO DE CARVALHO DE MENDONÇA}

O velho Código de 1850, em suas disposições gerais sôbre as sociedades comerciais, consagrava ao assunto quatro artigos de particular importância, do 303 ao 306, inclusive.

303 - "Nenhuma ação entre sócios ou dêstes contra terceiros, que fundar a sua intenção na existência da sociedade, será admitida em juízo se não fôr logo acompanhada do instrumento probatório da existência da mesma sociedade".

304 - "São, porém admissíveis, sem dependência da apresentação do dito instrumento, as ações, que terceiros possam intentar contra a sociedade em comum ou contra qualquer dos sócios em particular. A existência da sociedade, quando por parte dos sócios se não apresenta instrumento, pode provar-se por todos os gêneros de prova admitidos em comércio (art. 122), e até por presunções fundadas em fatos de que existe ou existiu sociedade".

305 - "Presume-se que existe ou existiu sociedade sempre que alguém exercita atos próprios de sociedade, e que regularmente se não costumam praticar sem a qualidade social. Desta natureza são especialmente:..."

Segue-se, em uma enumeração exemplificativa de nove incisos, uma série de fatos que, a título de presunções, permitem provar a

(3) CAIO MÁRIO DA SILVA PEREIRA - "Instituiçõos de Direito Civil", 1961, ed. Forense, vol. I, n. ${ }^{\circ} 59$, pág. 238. 
existência da sociedade irregular, incluidos casos como o do "emprêgo do pronome nós ou nosso nas cartas de correspondência, livros, faturas, contas e mais papéis comerciais" (VI), ou o "fato de receber ou responder cartas endereçadas ao nome ou firma social" (VII). A alínea final do art. 305 e o art. 306 enunciam e concretizam a regra da responsabilidade ilimitada dos sócios de sociedades irregulares, tendo porém o art. 306 alcance mais amplo.

A doutrina comercialista brasileira, anterior ao advento do Código Civil, tem em J. X. CARVALHO DE MENDONÇA e em seu famoso TRATADO seu mais alto cume. A contribuição do famoso comer cialista pátrio é particularmente importante, no assunto que nos interessa, dada a ampla e categorizada defesa por êle feita da personalidade jurídica das sociedades irregulares.

Note-se que o autor do "Tratado de Direito Comercial Brasileiro" escreveu em época em que não estava ainda superada a polêmica relativa à personalidade jurídica das sociedades mercantis que, vinda da França e da Bélgica (países em que se discutia também a personalidade jurídica das sociedades civis, entendida a palavra sociedade no seu sentido restrito) apaixonara grande parte dos juristas ocidentais. Escreve portanto no contexto de uma defesa da personalidade jurí. dica das sociedades mercantis, em geral.

No assunto que nos interessa - sociedades irregulares - é riquíssima sua argumentação. "O Código e as leis subseqüentes prescreveram sanção especial para as sociedades irregulares (...) a fim de Ihes dificultar a organização e a vida: porém as reconheceram - C. Com., arts. 303, 304, 305, - conferindo-Ihes capacidade matrimonial e representação em juízo - C. Com., arts. 303, 304 - considerando-as comerciante, sujeitando-as à falência - lei 2024-1908, art. 8.o, c. Dec. lei 7661/1945, art. 8.0, III - e, nesse estado, respeitando-lhes - patrimônio próprio, para evitar a confusão com os patrimônios dos sócios - Lei 2024/1908, art. 132, - Dec. lei 7661/1945, art. 128" (4).

Aduziu ainda resposta às opiniões de TEIXEIRA DE FREITAS $€$ CARLOS CARVALHO, que viam nas sociedades irregulares pura comunhão de bens ou interêsses. "Na comunhão, os consortes são coproprietários e podem dispôr livremente dos seus quinhões. As sociedades irregulares têm, ao contrário, partimônio próprio; os sócios não são co-proprietários do fundo social. Nelas existe a cooperação dos sócios, seu pronunciado característico" (5).

(4) - J. X. CARVALHO DE MENDONÇA, "Tratado de Direito Comercial Brasileiro", ed. Freitas Bastos, Rio, 1958, vol. III, n.o 610, pág. 89.

(5) - Idem, vol. III, n.o 612, pág. 92. 
Duas eram, portanto, as notas características da sociedade, inclusive quando irregular, que permitiam a J.X. CARVALHO DE MENDONÇA distinguí-la da comunhão - o patrimônio próprio, distinto do dos sócios e a affectio societatis, entendida como cooperação dos sócios.

\section{C) O CÓDIGO CIVIL. A DOUTRINA POSTERIOR. OS PROJETOS.}

O Código Civil Brasileiro trouxe, em seus incisos I e II do art. 16, uma enumeração taxativa dos tipos de pessoas jurídicas de Direito Privado. Tal enumeração - 1.0 diminuiu sensivelmente a importância da distinção entre sociedades civis e associações, enorme em outros sistemas, v. g. o francês; 2.0 cortou de modo absoluto, de lege lata, tôda e qualquer dúvida sôbre a personalidade jurídica das sociedades mercantis e civis.

Para o assunto de nosso trabalho, trouxe o Código mais especificamente os seguintes dispositivos:

Art. 18 - "Começa a existência legal das pessoas jurídicas de direito privado com a inscrição dos seus contratos, atos constitutivos, estatutos ou compromissos no seu registro peculiar, regulado por lei especial, ou com a autorização ou aprovação do govêrno, quando precisa".

Art. $20-\S 2 .^{\circ}$ "As sociedades enumeradas no art. 16 que, por falta de autorização ou de registro, se não reputarem pessoas jurídicas, não poderão acionar a seus membros nem a terceiros; mas êstes poderão responsabilizá-las por todos os seus atos".

Êstes dois textos de lei forneceram pràticamente a base essencial sôbre a qual trabalhariam os juristas posteriores na discussão do nosso problema. Tais artigos - 1. Tornaram clara a adesão do legislador brasileiro ao sistema das disposições normativas de que anteriormente nos ocupamos. Estabelecem um prévio elenco de tipos de pessoas jurídicas de Direito Privado - sociedades e associações, civis, sociedades mercantis e fundações. Fora dêsses tipos não há pessoa jurídica de Direito Privado. Admitem a regra básica da liberdade de constituição, prevista a formalidade do registro e aberta a exceção para determinados casos de sociedade para as quais é a autorização necessária. 2. Autorizaram aparentemente (art 20, \& 2. $)$ uma equiparação entre as sociedades que não se registraram por thes haver sido negada a autorização necessária e as que não se registraram por negligência, ignorância de seus sócios, nada obstando a que 
- fizessem. Em suma, o $\S 2 .^{\circ}$ do art. 20 pareceu equiparar as sociedades que não se registraram porque não o puderam (falta da autorização, in casu, exigida por lei ou, acrescentamos nós, porque não o puderam pòr ilicitude de objeto (I) às sociedades que não se registraram porque não o quiseram. (II) Só as sociedades do tipo (II), ou seja, só as sociedades que deixaram de registrar-se por não - terem desejado, inexistindo qua'quer obstáculo legal à satisfação de tal formalidade, é que constituem verdadeiramente as sociedades irregulares. Iguais às sociedades regulares no plano ontológico, do ser, e portanto da personalidade. As sociedades (I) exigem tratamento jurídico distinto, como será demonstrado infra. 3. Mantiveram (art. $20, \S 2 .^{\circ}$, in fine) o princípio que vinha da combinação dos arts. 303. e 304, ou seja, as sociedades irregulares não são encaradas como pessoas jurídicas no que tange à capacidade processual ativa; não podem acionar. São-no, porém, no que toca à capacidade processual passiva, podem ser acionadas.

Por outro lado, a importância dos princípios assentados pela velha legislação mercantil foi, no que tange às sociedades mercantis, acentuada pelo Código Civil, art. $16, \S 2 .^{\circ}$, verbis:

"As sociedades mercantis continuarão a reger-se pelo estatuido nas leis comerciais".

O que não impediu que o Código Civil viesse trazer normas gerais sôbre as pessoas jurídicas, aplicáveis inclusive às sociedades mercantis.

Muitos anos depois, em 1939, o Código de Processo Civil viria trazer um novo subsídio ao problema, que boa parte da doutrina viria a encarar como um argumento em favor da personalidade jurídica das sociedades irregulares.

Art. 673 - "Não havendo contrato ou instrumento de constituição de sociedade, que regule os direitos e obrigações dos sócios, a dissolução judicial será requerida pela forma do processo ordinário e a liquidação far-se-á pelo modo estabelecido para a liqüidação das sentenças".

De onde decorre que a lei processual regulou a liqüidação de sociedades nitidamente irregulares. Tal dispositivo fez 0 professor mineiro JOÃO EUNÁPIO BORGES, ao sustentar a personalidade jurídica da sociedade irregular, relembrar o pitoresco ensinamento de VIVANTE, segundo o qual "a liqüidação do patrimônio deixado por um defunto é prova evidente de que êle viveu, sem embargo de fal- 
tar-lhe o registro de nascimento". (6). O comercialista de Belo Horizonte aduz ainda, em favor de sua tese, de que compartilhamos, relativamente à personalidade jurídica da sociedade irregular mercantil, que "não fôsse a sociedade irregular uma pessoa jurídica comerciante, mas simples parceria de comerciantes em comunhão de interêsses, falidos seriam os sócios e não a sociedade irregular de que façam parte" (7).

Mas o fato incontestável é o seguinte: a doutrina civilística brasileira predominante, sobretudo após o advento do Código Civil, inclinou-se e continua a inclinar-se pela posição negadora da personalidade jurídica da sociedade irregular, muito embora sejam díspares as opiniões relativas à natureza jurídica dêsse quid a que tais juristas negam a personalidade - a sociedade irregular.

CLOVIS negou claramente a personalidade da sociedade irregular. Disse que tais sociedades existiam como sociedade, como contrato, como comunhões. $O$ que demonstra sua indecisão. Após negar a personalidade das sociedades irregulares (a tendência de nossa doutrina explica-se sobretudo a partir do tom categório do art. 18 "começa a existência legal... com a inscrição... - e do art. 20, § 2. ${ }^{\circ}$ 1. a parte - "as sociedades... que, por falta de autorização ou de registro, se não reputarem pessoas jurídicas...) entende que elas "existem todavia como sociedade, como contrato. Isso mesmo declara vam o Projeto Primitivo, art. 25, 2. ${ }^{a}$ parte e o Revisto, art. 24, 2. a $^{\circ}$ parte, acrescentando que os atos praticados em nome dela obrigariam pessoalmente o seu autor em relação a terceiro. Eliminada esta providência, resulta que a comunhão responde pelas dívidas sociais, cabendo a cada sócio uma parte nas dívidas, proporcional à sua entrada, arts. 1381 e 1396". (8)

Ressalte-se, em honra do sempre pranteado codificador, a muito maior coerência dos Projetos primitivo e revisto, comparados à solução final dada pelo legislador. Os projetos guardavam coerência interna na sua posição de negadores da personalidade jurídica da sociedade irregular. Não assim o Código.

CLOVIS percebeu agudamente a distinção entre sociedades que não podem e que não querem registrar-se. Para êle, as primeiras não têm existência legal; as segundas, as irregulares, possuem exisrência legal, embora não sejam pessoas jurídicas. Verbis - "As so-

(6) - JOÃO EUNÁPIO BORGES, "Curso de Direito Comercial Terrestre", Forense, Rio, 1959, vol. II, n. 264, págs. 47-48.

(7) - Idem, idem, pág. 50 .

(8) - ClOVIS BEVILAQUA, "Código Civil Comentado", 11.a edição, 1956, Francisco Alves ed., Rio, vol. I, com. ao art. 20, pág. 185, item 6. 
ciedades civis não autorizadas também não são pessoas jurídicas, pois que se não podem registrar. Nem são pròpriamente sociedades, porque se não podem constituir. Serão sociedades de fato, ou antes sociedades proibidas, pois que o Código lhes conserva o nome de sociedades; serão meras comunhões. Mas, não tendo existência legal, sendo nulo o contrato em que se fundaram (arts. 145, II e IV) não podem subsistir. E nisto diferem das sociedades civis não registradas que têm existência legal, ainda que sem as vantagens da personificação". Reconhece, adiante, que o Código responsabiliza a sociedade irregular, no interêsse de terceiros. (9).

WASHINGTON DE BARROS MONTEIRO fica aparentemente aquém de CLOVIS. Enquanto êste, como vimos, reconhecia à sociedade irregular uma existência legal sem as vantagens da personificação, o festejado mestre de São Paulo reconhece-lhe apenas uma existência de fato, não legai. Para êle, as sociedades irregulares "embora sem existência legal, podem adquirir por testamento. A lei exige, para tal fim, a existência da pessoa, não a existência legal. A existência de fato também é reconhecida pela lei para certos efeitos" (10). Ao que nos permitimos, modestamente, objetar que existência de fato reconhecida pela lei é igual a existência legal.

CAIO MÁRIO DA SILVA PEREIRA também nega a personalidade jurídica da sociedade irregular, expressão que sinonimiza com sociedade de fato.

O jurista mineiro, fiel à orientação entre nós dominante, fruto da interpretação literal do art. 18 e da primeira parte do $\S 2 .^{\circ}$ do art. 20 do Código Civil, entende que o registro das pessoas jurídicas, diferentemente do registro de nascimento das pessoas naturais, "tem fôrça atributiva, pois que, além de vigorar ad probationem, recebe ainda o valor de providência complementar da aquisição da capacidade jurídica" (11). Vai, porém, mais além em seu pensamento. Fiel ao seu modo de entender o sistema das disposições normativas, entre nós vigorante, como o sistema em que, ressalvados os casos excepcionais, previstos em lei, a vontade humana possui o poder, obedecidos requisitos predeterminados, de criar a pessoa jurídica, CAIO MÁRIO explica da seguinte forma a natureza da sociedade ou associação após sua criação pela vontade humana e antes do registro: "personalidade in fieri, permanece ela em estado potencial até que, preenchidas as exigências alinhadas na lei, converte-se em um stałus jurídico".

(9) - Idem, idem, ítem 7.

(10 - WASHINGTON DE BARROS MONTEIRO, "Curso de Direito Civil", Saraiva ed., São Paulo, 1958, Parte Geral, pág. 128.

(11) CAIO MÁRIO, op. cit., vol. cit., n. 59, pág. 238 
(12). Ficamos, portanto, com a impressão de que, gerada a pessoa jurídica pelo poder fecundante da vontade humana, a penosa gravidez só poderá chegar a têrmo feito o registro, que será o ato de nascimento. No intervalo, a pessoa jurídica (in fieri, no dizer de CAIO MÁRIO) seria um nascituro. A analogia já é clássica entre os autores que do tema se ocupam, mas seu simples enunciado revela o que tem de artificioso.

Seria porém improbidade científica de nossa parte para com o prof. CAIO MÁRIO reduzir a tão simples expressão seu pensamento, muito mais elaborado. Ao ocupar-se ex-professo do problema da sociedade irregular, o autor do Ante-projeto do Código de Obrigações propende inicialmente para uma solução de equiparação à comunhão. (13). Mas são seus próprios argumentos que demonstram a insustentabilidade de tal posição. Há, no caso das sociedades irregulares, um ato voluntário, "por isso mesmo hábil em tese a gerar uma pessoa moral" (14). Portanto, "a posição negativista do Direito em face de uma situação de materialidade palpável e irrecusável seria atentatória da realidade". (15). E adiante: "não é uma entidade vã, não é uma abstração ou uma figura inexistente, porque o direito a considera como uma unidade diferente da simples comunhão de direitos eventualmente originada da participação de mais de uma pessoa em uma relação jurídica". (16). Não se trata, também, como alguns pretenderam, de um caso de personalidade jurídica reduzida, aquilo que os franceses chamam de petite personnalité.

Com razão, nega CAIO MÁRIO a possibilidade de graus na personalidade. Verbis: "Não se pode também falar em "personalidade reduzida", pois que, acentúa-o proficientemente RUGGIERO, o conceito de personalidade é insuscetível de graduação. Seja quanto à pessoa jurídica, seja quanto à pessoa natural, a personalidade existe ou não existe. A pessoa natural é sempre dotada de personalidade. A pessoa jurídica ou a adquire ou não a consegue. Se não a tem, por falta de atendimento aos requisitos legais, não pode ser sujeito da relação jurídica". (17).

Que é então, a sociedade irregular, no pensamento de CAIO MÁRIO? "A compreensão do tratamento que a lei dispensa à sociedade irregular sòmente pode decorrer daquele princípio segundo o qual a aquisição de direitos é conseqüência da observância da nor-

(12) Idem, ibidem.

(13) Idem, n.॰ 60, pág. 243

(14) Idem, n. ${ }^{\circ} 60$, pág. 242

(15) Idem, n.०60, pág. 244

(16) Idem, n. ${ }^{\circ}$ 60, pág. 244.

(17) CAIO MÁRIO n. ${ }^{\circ} 60$ 
ma, enquanto que a imposição de deveres (princípio da responsabilidade) existe sempre" (18).

Temos então que a sociedade irregular não é pessoa jurídica mas que the podem ser impostos deveres, pelo princípio da responsabilidade. A explicação, data venia, nada explica, com ressalva do brilhantismo da exposição do douto civilista pátrio. Não pode ser sujeito de deveres quem não é pessoa. Se a sociedade irregular, pode ser devedora, então é pessoa jurídica. Se não, de que fantasma cobraria as obrigações o credor de tal sociedade irregular? Mais ainda - para ser-se responsável, é preciso ser-se pessoa.

SERPA LOPES incide na gasta e errônea explicação que vê na sociedade irregular um mero estado de indivisão ou comunhão de direitos", negando-lhe existência legal, por carência de registro. (19).

ORLANDO GOMES enfileira-se entre os negadores. Para êle, as sociedades e associações "não adquirem capacidade jurídica antes de satisfazerem a exigência legal". Em conseqüência, não valem os atos praticados no período que intercorre da constituição à aquisição da personalidade" (20) admitidas exceções ao princípio da irretroatividade da personificação no que tange aos fundadores e aos terceiros. Em outro ponto de sua exposição, frisa que "as sociedades irregulares ou de fato são grupos que não desfrutam da personalidade, ainda que se lhes reconheça certa capacidade de exercício dos direitos". (21).

Pedimos permissão para discordar do eminente mestre. Não cremos possível que algo que não é pessoa e, pois, não dispõe da possibilidade de adquirir direitos, possa, não obstante, ainda que restritamente, exercer certos direitos. Não julgamos concebível uma capacidade de exercício que assenta no suporte inexistente de uma capacidade de gôzo igual a zero.

Mas, na doutrina brasileira, o problema se torna mais apaixonadamente interessante e aparentemente insolúvel ainda no TRATADO de PONTES DE MIRANDA. E isso porque o notável jurista patrín cio negou a personalidade jurídica da sociedade irregular, como a generalidade da doutrina brasileira mas, ao mesmo tempo, forneceu copiosíssima argumentação que, a nosso ver, conduz de modo irresistível à afirmação da personalidade jurídica da sociedade irregular.

(18) M.M. SERPA LOPES, op. cit. vol. cit. pág. 510

(19) ORLANDO GOMES, "Introdução ao Direito Civil, forense ed., Rio de Janeiro 1958,

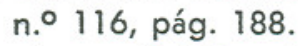

(20) Idem, n. ${ }^{\circ} 120$, pág. 191.

(21) llem, ibidem. 
Afirma PONTES DE MIRANDA que só com a inscrição ou o registro nasce a personalidade jurídica, mas sua própria argumentação põe a nu a incapacidade de tal tese de suster-se em pé sem leviair quem a defenda a tremendas contradições. No mesmo trecho em que afirma que o "ato constitutivo não se refere à pessoa jurídica; refere-se à entidade que vai ser personificada", PONTES DE MIRANDA define ato constitutivo como "todo ato dos que constituem (ou instituem) a pessoa jurídica in fieri". (22). Voltamos, portanto, à analogia com a gestação de pessoa humana. Aliás, PONTES DE MIRANDA entende que não devem ser excluidas "certas analogias entre o nascituro e a futura pessoa jurídica, na fase pré-personificação". (23) Discute se há ou não direito à personalidade antes da personificação e, no particular, após referir a posição das "teorias radicais", contrárias à afirmação do direito à personalidade, pondera que "o ato que negue a personalidade de alguma sociedade ou fundação pode dar ensêjo à ação declaratória positiva. Tanto ressalta que há relação jurídica. Por outro lado, qualquer pessoa pode ter interêsse em que se declare que a pessọ jurídica tem, ou não tem, certa capacidade de direito. (Constituição de 1946, arts. 153, § 1. ', 155 e 160", correspondentes, na Carta de 1967, aos arts. 161,§ 1.॰ 165 e 166, respectivamente). (24). Ora, em outro local, o genial tratadista já afirmara que, se a regra jurídica diz que "A pode ter direitos, ainda que só o direito b, A é pessoa porque a possibilidade de ter direitos já é direito de personalidade" (25). Ao estudar aquilo que chama de "associações e sociedades não-personificadas", que são justamente as que não cumpriram, ou não cumpriram ainda as formalidades de inscrição no Registro, volta a afirmar que, para que haja capacidade de direito, é necessária a personalidade. Dí-lo, ao considerar tautológico o dispositivo do art. 20 do Código Civil, pois, segundo entende, afirmar que as pessoas jurídicas têm capacidade de direitos é afirmar que as pessoas jurídicas são pessoas. (26).

E, não obstante, PONTES DE MIRANDA afirmará inúmeros casos de titularidade de direitos por parte da associação ou sociedade cujo ato constitutivo não foi, ou não foi ainda, inscrito.

Dirá que a entidade ainda não registrada pode praticar atos, e que os atos são seus. (27), com base nas palavras do próprio art. 20,

(22) PONTES DE MIRANDA. "Tratado de Direito Privado". ed. Borsoi. Rio vol. I, § 86, 1, pag. 358.

(23) Idem, § 85,3, pag. 356

(24) Idem, ibidem.

(25) Idem, § 75,2, pág. 284

(26) Idem, § 83,2, pág. 334.

(27) PONTES DE MIRANDA, "Tratado Direito Privado", ed. Borsoi, Rio, vol. I, $\S 83,2$, pag. 334 . 
$\S 2 .^{\circ}$ do Código, verbis, "responsabilizá-las por seus atos". Afirmará a separação de patrimônios e, por conseguinte, a existência de um patrimônio da entidade, que pode crescer ou diminuir, e a possibilidade de serem adquiridos direitos por ato de liberalidade em favor da entidade. (28). Dirá que a sociedade irregular pode ter nome, juridicamente tutelado (29), e reconhecerá sua capacidade processual passiva, de acôrdo aliás, com o art. 20. § 2. ${ }^{\circ}$, e, afirmando-o, reconhecerá a existência de órgãos da entidade: "as ações hão de ser dirigidas à Diretoria, ou a quem tenha qualidade de órgão para a vida exterior; b) a entidade é parte no processo e os membros não no são, razão por que podem ser arrolados e depôr como testemunhas; c) a reconvenção pode ser apresentada por todos os membros, mas, se a diretoria o faz, entende-se que o fêz como órgão e não como representante dos membros, de jeito que, ali, partes são os membros (...) e, aqui, parte é a entidade mesma. (...) Quaisquer ações e medidas processuais podem ir contra a entidade não-personificada. (...) Na posição de demandada ou de citada, notificada ou intimada, a entidade é pricessualmente capaz, e o órgão, que funciona, funciona como órgão". (30) Pouco depois afirmará que a "entidade não-personificada", como êle, teimosamente, continúa a chamá-la, se demandada, pode "reconvir, embargar de executados (...), pedir decretação de nulidade, de anulação ou de resolução, condenação nas custas, aplicação das penas dos arts. 63 e 65 do Código de Processo Civil, alegar compensação, interpor recurso extraordinário, propor ação rescisória, propor ação revocatória em processo de falência ou anulatória em concurso de credores, em que foi incluida como credora, bem assim alegar, na falência, ineficácia relativa; pedir indenização por danos sofridos em virtude de medida constritiva, cautelar ou executiva que foi concedida contra ela". Em certos casos, possui mesmo capacidade processual ativa a sociedade, associação ou fundação não registrada. Ela pode "no direito brasileiro, (a), ir a juízo ou postular perante as autoridades administrativas, se precisa ou the é negada a autorização para se criar (e.g., art. 20, § 1.०: não são só os componentes que têm legitimação ativa; tem-na a entidade não personificada". A qual pode "pedir (b) as inscrições: o órgão da entidade já aí funciona como órgão (Decreto 4857 de 9 de novembro de 1939, art. 129)" (31) Afirma ainda PONTES DE MIRANDA a sua capacidade contratual, e a possibilidade de tornar-se titular de direitos de crédito: "a natureza do ato coletivo é que explica poderem os figurantes tratar, desde logo, a entidade como polo ativo das relações de

(28) Idem, § 83,7, pag. 338

(29) Idem, § 83,4 , pág. 335

(30) Idem, § 83,8 , pág. 342

(31) Idem, § 83,9 e 83,8 , pags. $342 / 343$ 
crédito, como todos, algum, ou alguns dos figurantes, sem se pensar em relações entre êles a favor da pessoa jurídica futura. Não se trata de contrato a favor de terceiro, mas de contrato com a pessoa jurídica in fieri, tal como se, em vez disso, se faz da pessoa jurídica in fieri polo passivo de relações de crédito". (32) Afirma a retroatividade de efeitos do ato de inscrição no Registro do ato constitutivo da pessoa jurídica, o que faz evidentemente pensar em caráter declaratório da inscrição. "O contrato, por pós-eficacização entra, ipso jure, com a inscrição, a irradiar efeitos". (33) No mesmo local, volta a afirmar a existência de órgãos antes de inscrita a sociedade, associação ou fundação e, ainda no mesmo local, admite que a vontade dos particulares possa afastar o caráter de condição suspensiva de personalidade que, para êle, tem a inscrição. Assim, por vontade dos particulares, pessoa jurídica haveria logo após o ato constitutivo. Caso a inscrição se tornasse impossível, essa impossibilidade funcionaria como condição resolutiva da personalidade. A "impossibilidade da inscrição só opera como condição resolutiva se os figurantes conceberam a associação ou a sociedade como pessoa jurídica, afastando qualquer hipótese de funcionar sem personificação". (34) Quanto à repetida afirmação de que a entidade pretensamente não-personificada, ou ainda não, tem, entretanto, órgãos, lembremo-nos de que a existência de órgãos é prova mais que veemente de que pessoa existe. Deixemos o próprio PONTES. "Orgão é órgão, não é representante voluntário nem legal: (...) o órgão atua e recebe, como o braço, a mão, a boca, ou os ouvidos humanos; o ato e a receptividade são da pessoa jurídica (...) Exatamente porque o órgão não representa, a pessoa jurídica é capaz de obrar". (35)

Conclusão, inevitável, a partir de tôda essa longa reprodução de textos do grande tratadista brasileiro: êsse ser que pratica atos, que é responsável, que tem patrimônio, que pode ser demandado e defender-se, inclusive reconvindo e recorrendo - não esquecer que a reconvenção é açáo - que pode ter nome, jurídicamente tutelado. que pode ir a juízo, em determinados casos, que pode ser titular de créditos e débitos, e que tem órgãos, que é êle, senão uma pessoa? "Se A tem direitos, ainda que só o direito b, A é uma pessoa". E eis que $A$ não tem apenas o direito b, mas uma enorme lista de direitos.

Antecipemos, parcialmente as conclusões da parte que

(32) PONTES DE MIRANDA, "Tratado Direito Privado", ed. Borsoi, Rio, vol. I, § 86,3, pág. 361.

(33) Idem, § 86,3, pág. 362

(34) Idem, ibidem.

(35) Idem, § 75,3, pags. $286 / 287$ 
a esta se segue, dêste trabalho. A entidade ontològicamente pessoa, pessoa moral (no sentido que a esta expressão emprestam os autôres institucionalistas), cujo ato constitutivo não foi registrado, ou não o foi ainda, é, claramente, pessoa, já que não é possível ser-se mais pessoa ou menos pessoa.

$\mathbf{E}^{\prime}$ pessoa jurídica em rigoroso sentido técnico, já que não the falta a proteção legal, seu reconhecimento pela ordem jurídica. E' verdade que essa proteção e êsse reconhecimento são restritos, menores do que os dispensados às outras pessoas jurídicas, de vida plenamente regularizada. O que quer dizer que sua capacidade de direito é menor do que a das outras pessoas jurídicas - as regulares que pode gozar de um número menor de direitos, mas não quer dizer que seja menos pessoa, ou não-pessoa.

OS PROJETOS, atualmente em fase de tramitação pelo Poder Legislativo, agravam de certa forma a situação do Direito Brasileiro atual, pois que repetem alguns dos dispositivos do Direito vigente que fornecem argumentos contrários à personalidade jurídica das sociedades irregulares e não repetem aquelas normas que permitem concluir, como nós o fazemos, pelo reconhecimento, de lege lata, da personalidade jurídica das sociedades irregulares. Não há dúvida que os PROJETOS procuram, com coerência interna, afirmar não serem pessoas jurídicas as sociedades irregulares.

O PROJETO DE CÓDIGO CIVIL, redigido com base no ANTEPROJETO do professor ORLANDO GOMES, dispõe, em seu art. 62, que "a existência legal das pessoas jurídicas começa com a inscrição do ato constitutivo no seu registro, ou com a aprova:ção da autoridade competente, quando exigida".

O dispositivo repete, portanto, com correções de linguagem, o atual art. 18. Nada há, porém, de semelhante ao $\S 2 .^{\circ}$ do atual art. 20.

O PROJETO DE CÓDIGO DAS OBRIGAÇÕES ocupou-se da matéria ao tratar DOS EMPRESÁRIOS E DAS SOCIEDADES, com base no ANTEPROJETO do professor SYLVIO MARCONDES. O art. 1122 repete, no particular das sociedades, o art. 62 do PROJETO DE CÓDIGO CIVIL.

"A sociedade adquire personalidade jurídica com a inscrição no registro próprio e na forma da lei, dos seus atos constitutivos".

Classifica o PROJETO em seguida as sociedades em personificadas e não-personificadas. O SUBTíTULO referente a estas é, a nosso 
ver, parcialmente infeliz e parcialmente desnecessário. Pois que abrange dois tipos de sociedades "não-personificadas" - as "em comum" (que são as irregulares e as ainda não registradas) e as "em conta de participação". Quanto a estas últimas, em que pesem as respeitáveis opiniões em contrário, lamentamos que o PROJETO tenha regulado expressamente essa esdruxularia jurídica, compreensível apenas no velho Código de 1850, mas não num PROJETO de 1964 . Quanto às "em comum", examinemos o assunto mais de perto.

Art. 1124 - "os sócios, nas relações entre si ou com terceiros, sòmente por escrito podem provar a existência da sociedade, mas os terceiros podem prová-la de qualquer modo".

Art. 1125 - "Os bens e dívidas sociais constituem patrimônio especial, de que os sócios são titulares em comum".

Admite-se, por conseguinte, o princípio da segunda parte do art. 304 e, de certo modo, do art. 305 do Código Comercial em vigor que permite a prova por terceiros da existência da sociedade não-registrada. Admite-se mais a separação de patrimônio, a existência de patrimônio próprio da sociedade, mas, com a preocupação de resguardar a coerência, define-se tal patrimônio como patrimônio comum dos sócios. Volta-se então à velha tese da comunhão. Tese, data venia, totalmente insustentável.

Insustentável, não apenas por ser totalmente inadequada à vida de uma sociedade irregular o tratamento que a lei reservou para as comunhões, como agudamente demonstrou J. X. CARVALHO DE MENDONÇA e, em nossos dias, JOÃO EUNÁPIO BORGES (v. supra) como também por um motivo mais profundo - o de que a comunhão corresponde a realidade totalmente distinta da pessoa jurídica no próprio plano ontológico, do ser. Uma, a comunhão, corresponde a mera cotitularidade em comum de determinados direitos, realidade meramente estática. Outra, a pessoa jurídica, implica essencia!mente uma idéia de obra a realizar, realidade dinâmica, como tivemos oportunidade de demonstrar em nossa tese "CONCEITO DA PESSOA JURIDICA". (36) As sociedades, regulares ou irregulares, correspondem $\varepsilon$ essa realidade dinâmica, idéia de obra a realizar. Nunca a comunhão.

Verifica-se, a partir do exposto, que um gráfico da história do pensamento jurídico brasileiro mostraria que, nos últimos anos, há um crescente acentuar-se da tendência negadora da personalidade jurídica das sociedades irregulares, tendência que atinge seu ápice com

(36) J. LAMARTINe CORReA DE OliVeirA, "Conceito da Pessoa Jurídica", Curitiba, 1962, págs. 147, 148, 169, 170. 
os PROJETOS, especialmente o de CÓDIGO DE OBRIGAÇÕES. Ora, essa tendência choca-se profundamente com uma das conquistas essenciais do Código Civil Brasileiro, mantida aliás pelos PROJETOS: a de reconhecimento da personalidade jurídica a tôdas as sociedades, civis e comerciais, desaparecida a distinção romana entre universitates e collegia, dotados de personalidade, e societates, dela privadas Essa distinção viria a refletir-se na doutrina de língua francesa e de língua italiana, exarada sob o influxo do Código Napoleão e do veIho Código peninsular de 1865, na negação da personalidade jurídica das sociedades civis e mesmo das comerciais, de que o Direito daqueles países só muito tarde se libertaria. Ora, o Código brasileiro de 1917, em parte por influência da doutrina germânica, libertouse de tais anacronismos e reconheceu amplamente a personalidade jurídica de sociedades, associações e fundações. Os PROJETOS mantêm tal conquista. E é exatamente porque a mantêm que o PROJETO de Código de Obrigações, na obstinação de negar personalidade jurídica às sociedades irregulares, mas tendo de catalogá-las, refugia-se na inadmissível equiparação às comunhões.

\section{ESBÔÇO DE CONSTRUÇÃO DOUTRINÁRIA}

\section{A - Pressuposto essencial de solução - uma postura realista no plano da Filosofia do Direito.}

Há um equívoco básico que explica os atuais descaminhos, no particular, do pensamento jurídico brasileiro - o equívoco idealista - idealista no plano da teoria do conhecimento - tão caracterìsticamente típico dos rumos positivistas que infestam, de modo implícito, - pensamento de tantos de nossos cultores do Direito. Dizemos de modo implícito porque, frequentemente, nossos juristas assumem uma posição empírica, recusando-se a perquirir os problemas de $\mathrm{Fi}$ losofia do Direito. Como M. Jourdain, acabam fazendo prosa sem o saber. E como não é possível pensar sem que no fundo dêsse pensamento esteja um pressuposto \filosófico, assumem uma posição implìcitamente positivista e idealista. No fundo, não crêem na realidade do mundo exterior, preferindo refugiar-se em um mundo de idéias puras, para êles o único real. A partir de um ingênuo normativismo, crêem poder transformar a realidade fáctica pelo só enunciar da norma de Direito, esquecidos de duas realidades fundamentais - a vontade livre do ser humano, capaz de desobedecer à norma, e o pêso dos condicionamentos sociais.

No plano que nos interessa, essa concepção idealista atingiu seu ápice com os postulados da teoria da ficção legal e com sua conseqüềncia, o sistema da concessão estatal da personalidade, se- 
gundo o qual é o Estado o juiz único do caráter pessoal ou não dos organismos existentes na sociedade. A rigor, aliás, vai-se mais longe em tal modo de ver as coisas e transforma-se a personalidade em algo destituído de realidade, em mero dom simbólico do poder estatal. Nossos juristas de hoje não poderiam chegar tão longe, arraigada que está na consciência jurídica brasileira a tradição contrária ao sistema da concessão estatal da personalidade.

Em nossa tese de concurso, tivemos oportunidade de referir a propósito crítica de OLIVEIRA VIANNA aos nossos constituintes de 1891, que julgavam que, se alguém "enunciasse diante de uma roda parada a teoria do movimento, a roda principiaria a rodar pelo efeito da magnífica lógica formal da teoria", tendo em tal ocasião feito a aplicação da crítica do sociólogo fluminense à mentalidade dos homens da ficção legal. "Uma lei: e eis que do nada surgia uma pessoa jurídica. Outra lei: e eis que ela ao nada retornava. Estamos em pleno domínio da utopia". (37) Embora mitigado, parece ser êsse ainda o pensamento de muitos de nossos juristas que crêem poder 0 Estado, arbitràriamente, afirmar ou negar a personalidade jurídica dêste ou daquêle grupo ou instituição.

$\mathrm{E}^{\prime}$, aliás, o mesmo pensamento que está subjacente à tentativa infrutífera empreendida por certa recente enxurrada de decretos-lei de reformular o Brasil a partir do zero, fazendo tabula rasa de tôda a realidade viva e existente...

Coube aos autôres institucionalistas franceses e belgas, através de todo um pesquisar fecundo que passa por HAURIOU, RÉNARD, CLÉMENS, DÉLOS, tentar um primeiro esbôço de solução do problema, introduzindo uma distinção entre pessoa moral e pessoa jurídica. A primeira seria o ser apto à personificação. A segunda seria o mesmo ser após recebido o reconhecimento estatal de sua personalidade. Embora julguemos pouco feliz, por sua possível ambigüidade, a solução terminológica encontrada, não podemos deixar de verificar que aí está descrito o mecanismo essencial do fenômeno da interação Estado-Realidade Social no que tange ao problema das pessoas jurídicas.

Num plano de anterioridade lógica ao Direito estatal, existem os agrupamentos e instituições aptos a serem tratados como pessoas. $\mathrm{Na}$ realidade, no plano ontológico, são verdadeiras pessoas, são verdadeiros sujeitos de direitos, embora sua personalidade não seja idêntica mas meramente analógica à do ser humano.

(37) J. LAMARTINE CORRÊA DE OliveIRA, "Conceito da pessoa jurídica", Curitiba, 1962, pág. 36 
Num plano distinto, lógica e cronològicamente posterior, o Estado reconhece, declara realidade que preexiste a tal declaração. $E^{\prime}$, aliás, a posição adotada, entre nós, pelo decreto-lei 9.085 de 25 de março de 1946, que em seu art. $1 .^{\circ}$ regula o registro dos atos constitutivos-anteriores ao registro e em seu art. $4 .^{\circ}$ reconhece a vida, anterior ao registro, de sociedades e associações. Na prática, nós sabemos as concessões práticas a que têm sido levados juristas contrários a nossa posição doutrinária ao admitir numerosíssimas exceções ao princípio por êles formulado de uma suposta irretroatividade dos efeitos da personificação. Em verdade, o que sucede é que o reconhecimento estatal da personalidade - reconhecimento no sentido de tomada de conhecimento oficial que se faz através do registromeramente declara, e tem por isso os efeitos retroativos que PONTES DE MIRANDA, com a lucidez e agudeza habituais, percebeu, como vimos supra.

Não se trata, porém, tal ato de reconhecimento estatal de algo assemelhado a mera constatação. Realmente, êsse reconhecimento estatal é requisito extrínseco - mas não constitutivo, da personalidade. Cabe ao Estado uma função investigativa que verifica se a instituição que se pretende registrar possui realmente as características ontológicas de realidade institucional análoga à pessoa humana.

De um lado, e prévia a qualquer ação estatal, a realidade, viva no mundo social, associação, sociedade, fundação. Suas causas em terminologia aristotélico-tomista, podem ser assim decompostas - causa maferial: as pessoas humanas que entram em jôgo-membros da sociedade ou associação, administradores da fundação, bens e instrumentos postos a serviço da realização dos fins da entidade - em. suma, tudo aquilo por meio de que (quo) a pessoa jurídica vive e funciona; causa formal - a unificação através de procedimento consciente e livre: unificação de esforços, instrumentos, pessoas humanas e seus atos, com vistas a um fim. Razão e vontade humanas.

Em plano distinto, o reconhecimento estatal. Ouçamos GONELLA:

"Insistendo sul carattere umanistico dell'ordinamento esteriore all'vomo, che riconosce la personalità dell'vomo. Sono gli vomini che si riconoscono come persone". (38). "La volontà dell"uomo è costitutiva della persona giuridica: bisogna però fissare le condizioni dell' eficacia della volizione costitutiva. Cioè, il sorgere della persona giuridica potrà essere abbandonato all'arbitrio della volontà, poichè la volontà risulta vincolata dall'avveramento di determinate condizioni na-

(38) GUIDO GONELLA. "La Persona nella Filosofia del Diritto". Milano. 1959. ed. Giuffré. pág. 250. 
turali. Quindi, il dire che la personalità non è frutto dell'arbitrio individuale, non porta a concludere che la personalità è creazione del diriłto obiettivo: fra le due posizioni vi sono altre posizioni intermedie. La personalità può avere vita dal volere condizionato ad esigenze razionali e reali, cioè all'averarsi di determinate condizioni di ordine logico e di ordine empirico, di determinate armonie fra postulati della ragione e accadimenti della realtà. Accettando questo principio della costituzione della persona giuridica per opera del volere condizionato dell'vomo; non si viene a ridurre il riconoscimento statuale a pura constatazione: può essere anche perfezionamento e conferma, ma conferma di ciò che preesiste e non creazione dal nulla. Si riconosce ciò che esiste; e l' esserci è anteriore all' essere riconosciuto. La stessa funzione del controllo della liceità dello scopo è una funzione investigativa dell'esistenza di quelle condizioni reali che sono necessarie perché si abbia la persona. Del resto, anche i fautori del valore costitutivo del riconoscimento finiscono con l'ammettere (in contradizione con la loro tesi) che il riconoscere è un requisito estrinseco. Evidentemente, ciò che è estrinseco non può essere considerato come costitutivo" (39).

Passemos às aplicações.

B. O problema da personalidade jurídica da sociedade irregular no plano de uma doutrina geral da pessoa jurídica.

Vistas essas essenciais conclusões sôbre a interação Direito Positivo-Realidade Social e a sua áplicação aos dois momentos:

I - Instituição social ontològicamente pessoa em sentido analó gico;

II - Reconhecimento pelo Estado de tal realidade.

Vejamos agora como construir uma doutrina em tôrno de tal problema, aplicável ao Direito Brasileiro, e como nela situar o problema da sociedade irregular.

a) - Aos olhos, pois, do jurista, o Estado, por intermédio da lei, no expressivo dizer de MICHOUD, "classe parmi les sujets de droit les groupements dont la constitution intime correspond à la notion de sujet; et, en reconnaissant la personnalité de ces groupements, l'État ne fait qu'appliquer cette règle de droit". (40). Há, assim, por parte da ordem jurídico-positiva um trabalho prévio de całalogar,

(39) GUIDO GONELLA, "La Persona nella Filosofia del Diritto", Milano, 1959, ed. Giuffré, pág. 251.

(40) MICHOUD, Léon, "La théorie de la personnalité morale et son application au droit français "librairie G-nérale de Droit et Jurisprudence", 1.a parte, 3.a ed., Paris, 1932, pág. 130. 
dentre as instituições que a vida social criou, aquelas cuja estrutura ontológica é suscetível de ser tratada como pessoa, como sujeito de direitos. Entre nós, fundações, sociedades civis e mercantis e associações. Muito justamente, a lei pré-excluiu o condomínio do elenco de instituições dotadas dessa característica pessoal. E pré-excluiu também a família, que, entretanto, é ontològicamente pessoa, como tivemos oportunidade de demonstrar em outro trabalho.

b) - Reconhecidas e catalogadas as categorias, o Estado, no sistema normativo, exige normalmente apenas certos requisitos formais, destinados a evitar preventivamente o reconhecimento pelo Estado de personalidade a grupos ou fundações que não estejam estruturalmente aptos a serem reconhecidos como pessoas jurídicas. Tais requisitos formais funcionam como sinais ou sintomas da adequação entre o grupo ou instituição, in casu, e o tipo (sociedades, associações ou fundações, no Direito Privado Brasileiro) a que o Estado reconhece características ontológicas de pessoa. Visam evitar que o Estado se engane, reconhecendo como pessoa quem não o é, criando com isso problema de aparência e de boa fé de terceiros.

c) - Quanto ao caso de entidades de conteúdo, objeto ou fins ilícitos, elas nunca foram nem poderão ser pessoas. Não são "fonte de atividade orientada para o Bem Comum", requisito sublinhado por CLÉMENS entre os essenciais, no plano ontológico, à personalidade de um grupo ou instituição. (41) Pode aí surgir problema de aparência. O Estado recebe o registro, por inadvertência do oficial, ou da Junta Comercial, ou da autoridade encarregada de aprovação dos Estatutos, no caso das fundações (Cod. Civil Brasileiro, art. 27) de uma entidade de fins ilícitos. Mas a personalidade não foi adquirida, sendo nulo, a rigor, tal registro.

d) - No caso, porém, de determinados grupos, o Estado exige a autorização prévia para funcionamento. $E^{\prime}$ o que ocorre, em nosso Direito, com sociedades de seguros, Bancos, etc., MICHOUD teve ocasião de solucionar o problema, mostrando a compatibilidade de tal exigência com as normas e princípios do sistema normativo ou das disposições normativas. "Cette idée n'est pas absolument incompatible avec la possibilité d'éxiger, dans certains cas au moins, une reconnaissance spéciale, portant sur chaque personne morale individuellement, et non sur toute une catégorie; car on peut présenter cette éxigence comme devant permettre à l'État de vérifier, dans chaque cas particulier, si le groupe qui aspire à la personalité remplit les conditions exigées pour cela par le droit". (42). Se em determina-

(41) CLÉMENS, Réné, "Personnalité morale et personnalité juridique", Recueil Sirey, Paris, 1935.

(42) MICHOUD, ibidem. 
dos casos concretos, o Estado negou reconhecimento por um ato de mero arbítrio à personalidade de uma companhia de seguros, por exemplo, negando-lhe a autorização para funcionamento, sem que o problema fosse de ilicitude de objeto, a pessoa moral, para usar a linguagem institucionalista, não se transformou em pessoa jurídica por falta do requisito meramente extrínseco do reconhecimento estatal. Pode surgir aí, em concreto, disparidade entre o mundo fáctico, em que a pessoa existé, como instituição ontològicamente dotada de personalidade, e o mundo jurídico de Direito Positivo, que não a acoIheu como pessoa jurídica. Essa contradição é sempre perniciosa. Ora, apesar de o art. 62 do decreto-lei 2627 de 1940, a chamada lei das sociedades por ações, limitar os casos em que "a sociedade anônima ou companhia não satisfaça as condições econômicas, financeiras ou jurídicas especificadas na lei, ou quando sua criação contrariar os interêsses da economia nacional", tudo, portanto, dentro dos princípios que estamos defendendo de só prefixar limites de natureza estrutural e ética, o fato é que, na prática, tem sido entendido que tal ato é de arbítrio estatal. De lege ferenda, entendemos que seria conveniente adotar sistema em que fôsse mais claramente suscetível de exame judicial o ato do Poder Público, o qual perderia assim todo caráter de arbítrio. Em suma, o sistema da letra a da enumeração feita por PONTES DE MIRANDA: "a) se a lei enumerar os requisitos, não deixando ao livre arbítrio da autoridade a apuração de merecê-la, há direito à autorização estatal, ou à aprovação, satisfeitos os requis.itos". (43).

e) - Quando o caso é de existência legal de autorização para constituição, como é o caso do art. 63 do decreto lei 2627/1940 - sociedades para as quais é exigida normalmente autorização para funcionamento, quando se queiram constituir por subscrição pública - é evidente que, negada a autorização, frustrada a subscrição pretendida, não chega a haver constituição, não chega a nascer nem mesmo a pessoa moral, a realidade institucional.

f) - Quanto às FUNDAÇÕES, PONTES DE MIRANDA afirma que "a fundação nasce de declaração de vontade do fundador, em escritura pública ou testamento, sem intervenção do Estado que, através do Ministério Público, apenas as fiscaliza' (. . .) "Não há negócio de fundação sem a vontade de se criar pessoa jurídica. (44). E, mais adiante - "o sistema jurídico brasileiro não tem a autorização ou concessão esłatal (aliłer, o alemão, que adota o sistema da concessão". (45) $E^{\prime}$ verdade que, contraditòriamente, o genial tratadista entende

(43) PONTES DE MIRANDA, Tratado, 1.0 volume, pág. 359, § 86,2

(44) Idem, § 104, pág. 453

(45) Idem, § 106, pág. 462 
possuir o registro um caráter constitutivo, (46) afirmando a existência de criação e personificação como fases separadas. Haveria assim fundações não personificadas. O pressuposto é falso, tanto assim que, em outra página, o próprio PONTES DE MIRANDA (47) negou às pretendidas fundações não registradas, por desejo de sigilo, o caráter de fundações - seriam associações ou doações em prestações periódicas ou contratos de constituição de renda. O eminente tratadista levantou aí uma ponta do véu que encobre a realidade dos fatos o registro é, sem dúvida, formalidade necessária para assegurar proteção estatal à pessoa jurídica. Opera, porém, ex tunc, como tôda formalidade declaratória. A fundação foi criada antes. O Estado apenas exige o registro, como formalidade extrínseca, como bem acentuou GONELLA, no desempenho de função de assegurar publicidade, aperfeiçoamento e confirmação.

Quanto à aprovação dos Estatutos exigida por nossa lei, é evidentemente um caso de exercício dessa função investigativa da exis. tência de condições reais necessárias à personalidade. De condições ONTOLÓGICAS.

\section{C - Conclusão - a personalidade jurídica da sociedade irregular.}

Resulta irresistível a conclusão. Há, no sistema jurídico brasileiro, (a) sociedades, associações, fundações.

Há entidades que não se registraram por não poderem fazê-lo, por ser ilícito o seu objeto (obstáculo ético) ou por não corresponder sua estrutura à de uma das categorias de Direito Privado associações, sociedades, fundações-obstáculo estrutural. Tais entidades (b) não são pessoas. Nunca o foram. Ético ou estrutural, o obstáculo é ontológico, no plano mesmo do ser.

Há (d) sociedades a que o Govêrno negou autorização para funcio. namento. (art. 62 do decreto-lei 2627). Das duas uma - ou o Govêrno agiu bem, e ou por motivos éticos ou estruturais, em ambos os casos por motivos ontológicos, não são elas verdadeiramente pessoas, ou exorbitou, criando disparidade entre a realidade social e a ordem jurídico-positiva. Cabe aperfeiçoar o sistema de controle judi. cial para tais atos.

Há (e) entidades que não chegaram a constituir-se por lhes ter sido negada a autorização para subscrição pública (art. 63 do decreto-lei 2627). Não são nem mesmo realidades institucionais. Não são.

(46) Idem § 107, pág. 466

(47) Idem, pág. 454. 
Não chegaram a ser. Pode, no máximo, ter sido ferido direito das pessoas naturais.

Há (f) fundações que não quiseram registrar-se. Dado o caráter peculiar do ser da fundação, fundar eficazmente exige vontade de criar pessoa jurídica. A suposta fundação irregular será redutível na maior parte das vezes a uma associação irregular.

Há, finalmente, sociedades e associações que não cumpriram, por não o terem desejado, as formalidades finais de registro.

São pessoas jurídicas, pois que têm alguns direitos, e basta ter algum direito, ou só um direito, para ser pessoa. E elas têm varios direitos, reconhecidos pela ordem jurídico-positiva. E não é possível ser-se sujeito de direitos sem se ser pessoa, o que seria uma contradictio in termininis.

São, porém, pessoas, a quem a lei, por motivos de ordem pú. blica e com caráter de sanção, privou parcialmente da própria capacidade de gôzo. Gozam de alguns direitos, não de todos. Mas são pessoas, tanto quanto as outras, pois não há graus na personalidade. Sua situação é semelhante à do estrangeiro, que não goza de certos direitos em face da ordem jurídica brasileira, como o de ser diretor de empresas jornalísticas. Nem por isso é menos pessoa. E' pessoa, com restrições à capacidade de direito ou de gôzo.

(Só isso basta para demonstrar a superficialidade de certos escritores, que sinonimizam personalidade e capacidade de direito).

Restaria transformar essa construção doutrinária em artigos de lei. $E^{\prime}$ a sugestão que aqui deixamos, no ensejo da discussão dos PROJETOS. Cremos que o sistema global que propomos é o mais consentâneo com o direito natural de associação, com a ordem jurídica democrática e com os bons princípios de uma visão humanística do Direito.

Restaria também transpô-la para o campo do Direito Administrativo, e do Direito Público, em geral. O que já é outra história, fora dos limites e das modestas ambições dêste trabalho... 